\title{
Respuesta a: ¿estamos educando o entrenando?
}

\author{
Response to: Are We Educating orTraining?
}

\author{
Réponse à : Éduquer ou entraîner?
}

\section{James Scott Johnston}

Queen's University, Canadá

$\mathrm{E}$ L FRACASO DE LA PEDAGOGía en el ámbito de la educación científica habla sobre una falta de voluntad política para instituir aquellas prácticas que la investigación ha comprobado que son más efectivas. Estas prácticas son costosas: clases de cupo limitado, tareas de investigación semi-estructurada, pequeños grupos de aprendizaje, proyectos en vez de memorización y, sobre todo, tiempo para avanzar de la identificación de problemas a la indagación y luego a las soluciones; estas consumen recursos y financiamiento que la mayor parte de las universidades (para que mencionar a las escuelas secundarias) parecen reticentes a invertir. Tristemente, parece poco probable que este escenario mejore, dados los crecientes llamados a la probidad y a la responsabilidad fiscal de parte de las universidades en Norteamérica. Es muy alta la probabilidad de que haya que hacer más con menos.

Sin embargo, si realmente nos interesa mejorar la pedagogía, entonces debemos estar preparados para enseñar más allá del límite de las prácticas actuales. Ana Jofre espera que, con un fundamento científico suficiente basado en la memoria, los estudiantes lleguen a la indagación científica genuina, y al descubrimiento. El descubrimiento es el objetivo de la indagación científica (scientific inquiry); a su vez, la indagación científica es ese conjunto de métodos, técnicas, actitudes y disposiciones que, perfeccionados por la observación y la práctica, arroja resultados anticipados. Este comparte muchas de las características y los rasgos del arte dirigido de manera intencionada, por lo cual se le puede llamar arte investigativo. Según Jofre, cuando fomentamos la indagación científica genuina, estamos enfatizando no sólo el contenido sino el contexto en que la ciencia ocurre. 
No soy muy optimista acerca de empezar con la memorización, aunque quizá esto se deba al poco énfasis que se ha otorgado a la verdadera indagación científica en las escuelas secundarias. A mi parecer, si los alumnos tuvieran la oportunidad de resolver problemas a la manera de un arte investigativo en las escuelas secundarias estarían mejor preparados para la memorización que se enfatiza en las clases de introducción a las ciencias en las universidades. Desafortunadamente, parece que lo que memorizan sólo se apila sobre lo memorizado anteriormente y los estudiantes deben esperar hasta el segundo año o más para entrar a la etapa experimental de sus estudios científicos. Esto resulta lamentable ya que es el aspecto investigativo y experimental de los estudios científicos, más que la fórmula o las conclusiones, lo que importa desde la perspectiva de un investigador. Como en el caso del arte, guiar la investigación hacia un resultado fijo es lo satisfactorio, no el almacenaje de las conclusiones de otros.

Aunque no logro prever cambios en el currículum de las escuelas secundarias, aún puedo afirmar que la experimentación de los alumnos en un ambiente controlado resulta mucho más propicia para dominar el arte de la indagación científica que memorizar fórmulas o conclusiones. La memorización de fórmulas o conclusiones representa sólo un medio, quizá uno necesario dada la situación actual, pero es sólo un medio para conseguir un fin. En caso que, como sugiere Jofre, queramos indagadores científicos por sobre todo, nuestro objetivo debería ser la indagación científica como un proceso de deliberación e investigación, que empiece con la identificación de problemas y concluya en un resultado definido. Debemos desarrollar la voluntad política para llevar esto a cabo. 